\title{
Virtual Chemistry Laboratory as Pre-Lab Experiences: Stimulating Student's Prediction Skills
}

\author{
Yenni Kurniawati ${ }^{1}$, Fitri Refelita ${ }^{2}$, Afrida $^{3}$ \\ \{ yenni.kurniawati@uin-suska.ac.id \}
}

Chemistry Education Departement, State Islamic University of Sultan Syarif KasimRiau, Indonesia ${ }^{1}$
Islamic Education Departement, State Islamic University of Sultan Syarif KasimRiau, Indonesia ${ }^{2,3}$

\begin{abstract}
The student's prediction skills in chemistry experiments areimportant skills for pre-service chemistry students to stimulate students reflective thinking at each stage of chemistry experiments, qualitatively and quantitatively. A Virtual Chemistry Laboratory was designed to provide opportunities for students to practicing kinds of chemistry experiments everywhere, anytime, and repeatedly, before exercising the real experiment. This research was conducted by mixed method with triangulation data, in which the Virtual Chemistry Laboratory content was constructed using the Model of Educational Reconstruction and developed to enhanced students ability to predict the experiment results and analysed the cause of error, calculating the accuracy and precision with carefully in using chemicals. This research bring out a new and simple experiment design inside Virtual Chemistry Laboratory, and the implementation showed student's transformation to executing important decision, extremely beware with accuracy, but still had low concern in precision. It enhancing students level of reflective thinking skills related to their prediction skills 1 until 2 stage This study recommends for different subject matter to provide more opportunities for students to expand another chemistry experiments.
\end{abstract}

Keywords: Virtual Chemistry Laboratory, Prediction Skills, Chemistry Experiments, Pre-Lab Experiences

\section{Introduction}

Prediction skills arenot commonlyknownby teachers as doctors. It's rarely researched dan get attention by experts in chemistry learning, even though it is an important skill. Prediction skills are usedto determine chemical experiments results from the beginning, and preventively could avoid the danger of mistake in chemical experiments, and also become animportant skills for making a decision about synthesize new compounds with an inovativeand old modified method (Kurniawati, 2017).

Prediction skills are a part of higher-order thinking skills(King, Goodson, \& Rohani, 2004), that indicate intelligence, wisdom, accuracy in making decisions and reflecting good abilities in understanding and implement science process skills. Teacher with smart prediction skills will be able to interconnected theories and practices with past experiences, to decide a smart solution or find a way out of various problems (Kurniawati, Permanasari, Muzakir, \& Rohman, 2015).

However, previous studies indicate that the prediction skills of preservice chemistry teacher are one of the most difficult indicators of high order thinking skills to be provided 
(Kurniawati, 2017). Accurate predictions make people not only solve problems and make smart desicions, they also wise and visionary. They are able to reflect well on all the problems they experience today to the past and the future.

Prediction skills are needed by a teacher, including a chemistry teacher. When a chemistry teacher has an error prediction, it could beinduce a negative impact on chemical learning activities, especially in chemical experiments, even could produce a bad decision that endanger students. Professional chemistry teachersshould have prediction skillswell (Agrawal, Gans, \& Goldfarb, 2018). They have to teach theoretical chemistry or experimentation by paying attention to every decision making, avoiding many problems in chemical experiments, which can affect the safety of their students in laboratory.

Prediction skills can be improved in line with increasing knowledge and experience (Schaeffer, 2011). Capable knowledge, sufficient experience in chemistry experiment and the skills to connect the two are needed(Kurniawati et al., 2015). Therefore, adequate experience in chemistry experimentals are needed to be practice continuously, which are synergic with the enhancement knowlege teoretically, and making reflection on process andresults experimental as habit. Repeated experiments are also needed to make the students understand chemical concepts behind the experiments well and help them through the process of reflective thinking. However, this is difficult to be facilitated by faculty.It will require a lot of additional costs, time and staff to be able to fulfill it. Students experiences in the laboratory became limited, obstructed by the cost, time and other constraints. Whereas, to improve students ability of prediction skills, experience repeatedly and continuously are a must, to take place it intelligently and better (Sirhan et al., 2001). A smart solution is needed to overcome this problems.

Experiments through virtual activities or known as Virtual Laboratory is one of the experimental practice solutions that need to be taken into account. Virtual Laboratory is a laboratory experiment without a real laboratory with certain limitations, which can help students provide more possibilities in connecting between theoretical and practical aspects, without requiring the help of real tools, which are electronically programmed in a computer to simulate experiments which resembles real conditions in a virtual laboratory(Keller \& Keller, 2005). Virtual Laboratory is an experiment in an environment that stimulates the learning process in a real laboratory, because it provides tools, materials and other laboratory equipment in a virtual way to get experiment subjectively by individuals or in a group anywhere and anytime(Babateen, 2011).

VCL helps students conduct experiments without having to anxious about cost constraints, the danger of chemicals, and without being constrained by space and time(Hovakimyan, Sargsyan, Ispiryan, Khachoyan, \& Darbinyan, 2013), and does not require much staff (Bakar et al., 2013). VCL also can provide opportunities for students to be able to have experience and practice repeated experimental skills without being limited by space and time, at a more affordable in cost and minimal risk.

VCL can help students understanding the theory behind experiments and be able to help students connect the experiments they do with the initial knowledge they have(Levy \& Wilensky, 2009). Other research also shows that the Virtual Chemistry Laboratory can help students strengthen the foundation of knowledge on some basic concepts of chemistry, improve construction thinking and help improve students' thinking skills, especially in problem solving(Aksela, 2005), and helps understanding chemistry by involving cognitive understanding skills at three levels: macroscopic level, symbolic level and microscopic level(Herga, Cagran, \& Dinevski, 2016) or microscopic / molecular scale (Tatli \& Ayas, 2013). VCL also addresses a variety of learning constraints related to improving 
understanding of science process concepts and skills (El-sabagh, 2011), creating habituation to the work environment in the laboratory (Dalgarno, Bishop, Adlong, \& Bedgood, 2009), increasing scientific attitudes(Ay \& Yilmaz, 2015), as well as improving students' reflective thinking skills (Kurniawati, 2017). In addition, the experience of virtual experiments can also help students frame problems and find solutions, before real experiments are carried out (Rodgers, 2002; Schon, 1983).

The important thing in this research is that the virtual designed must have a composition of contents and construction that can bridge the understanding of concepts, reflective skills and experimenting skills, and can be assessed. In its construction, VCL can also be filled with chemical knowledge that supports experiments and designs that support the student's reflection process. Therefore, in integrating activities that can develop the predictive skills of prospective teachers in the educational environment must be designed VCL construction in a variety of scenarios so that the tendency becomes a positive attitude and a good stimulus(Fariza Khalid, 2015; Strampel \& Oliver, 2007). Therefore, research is needed on how to design VCL which are expected to be a means to help experimental skills and also need to be investigated how far it could stimulate the improvement of prediction skills of preservice chemistry teacher.

\section{Methodology}

This research was conducted by mixed method design in which qualitative and quantitative data collection was carried out using the exploratory model (Creswell, 2002) and integrated the Model of Educational Reconstruction (Duit, Gropengießer, Kattmann, Komorek, \& Parchmann, 2012) as a way of stage to design VCL. This research was carried out in two phases, the VCL design/ construction phase, and the VCL implementation phase.

In accordance with the Model of Educational Reconstruction (MER), the design phase begun with content structure analysis, followed by empirical studies conducted to explore students' difficulties and weaknesses in predicting experiments, and the extent to which they were able to interelate concepts they understand to the experiments they were doing. The final step was to make a VCL according to the content that has been compiled. VCL courseware was built then using Adobe Flash CS-6 software.

In the VCL implementation phase, 4th semester of preservice chemistry teacher in the chemistry education departement of one of the universities in Indonesia were used asthesample. The VCL implementation was carried out on three homogeneous classes (which have been tested for homogeneity), by giving a different practicum model treatment. In class A, VCL was given as a substitute program of the real experiment (X1), class B was practicingthe real experiments only (as a comparison), and class C used VCL as an exercised before doing the real experiment (X3) or class which was given the pre-lab experiences. These three test classes were intended to determine the differences in Prediction Skills in the sample that perform different forms of experiments, based on the scale adapted from Paul and Elder, 2004 and Spark-Langer et al. (1990), as shown in Table 1. 
Table 1.The Scale of Prediction Skills

\begin{tabular}{|c|c|}
\hline Scale & Description \\
\hline 1 & Prediction without descriptive language \\
\hline 2 & Predictions with simple / simple \\
\hline 3 & descriptions \\
\hline 4 & $\begin{array}{l}\text { Predictions with explanations according } \\
\text { to general terminology }\end{array}$ \\
\hline 5 & $\begin{array}{l}\text { Predictions with explanations based on } \\
\text { personal habits or preferences }\end{array}$ \\
\hline 6 & $\begin{array}{l}\text { Explanation with the principle or theory } \\
\text { given as rationalization }\end{array}$ \\
\hline 7 & $\begin{array}{l}\text { Explanation with principles or theory and } \\
\text { consideration of context factors }\end{array}$ \\
\hline & $\begin{array}{l}\text { Explanations with broad scientific } \\
\text { considerations but rooted in problems }\end{array}$ \\
\hline
\end{tabular}

The scale in each indicator was used to determine the extent to which students experience stimulation due to VCL assistance.

\section{Result And Discussion}

\subsection{Vel Construction}

In accordance with the stages of MER, VCL construction which began with content structure analysis, resulted in the synthesis of inorganic compounds as VCL content because they had the expected characteristics. In terms of chemical concepts, the synthesis and characterization of inorganic compounds is an experiment that involves understanding concepts that relate to the characteristics of elements and inorganic compounds, chemical bonds, solution chemistry, reactions of inorganic compounds, thermochemistry, equilibrium, reaction velocity, stoichiometry, qualitative and quantitative analysis, and chemical instrumentation. In terms of the ability to experiment, the synthesis and characterization of inorganic compounds is an experiment that involves many basic abilities of experimenting for a chemistry teacher candidate, starting from the ability to determined tools and materials, conducting substance preparation, using chemical instrumentation, designing experiments, assembling simple tools, reacting, warming up, doing qualitative and quantitative analysis, and observing experimental results, to draw conclusions then.

From the results of an empirical study it was known that there are still students who have difficulty conducting experimental activities that are very basic and should have mastered them, such as arranging glass tools for experimental needs such as reflux, distillation making a solution with a certain concentration, recrystallizing and others. These results of the analysis that have been conducted provide scientific clarification of the relationship between the chemical concepts given in the course of inorganic chemistry and experiments carried out in inorganic chemistry labs with subject matter choices to be made VCL after considering important aspects outside the content structure, such as time efficiency, cost,staff and chemical hazards, through textbook analysis. Reconstruction of the structure of this material also 
involves the opinions of educators and students regarding their difficulties in understanding the material related to the experiment.

VCL development is carried out through the reconstruction of material structures that conecting theory with experiment and its reflective thinking position as seen in Figures 1 to 3 .

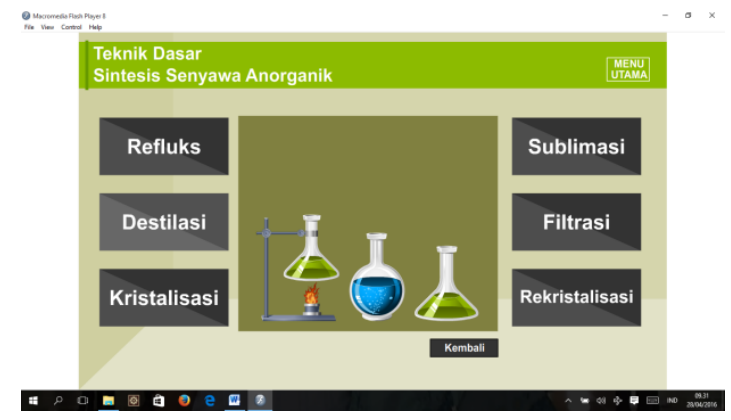

Fig.1. VCL menu that supporting experiments

The VCL menu as shown in Figure 1 explain that VCL can be filled with science content related to experiments, to provide students can be helped in bridging knowledge with experiments. Content selection was the result of content structure analysis at the beginning of the MER stage, as well as the core content of the VCL, namely virtual experiment screencapture as shown in Figure 2.

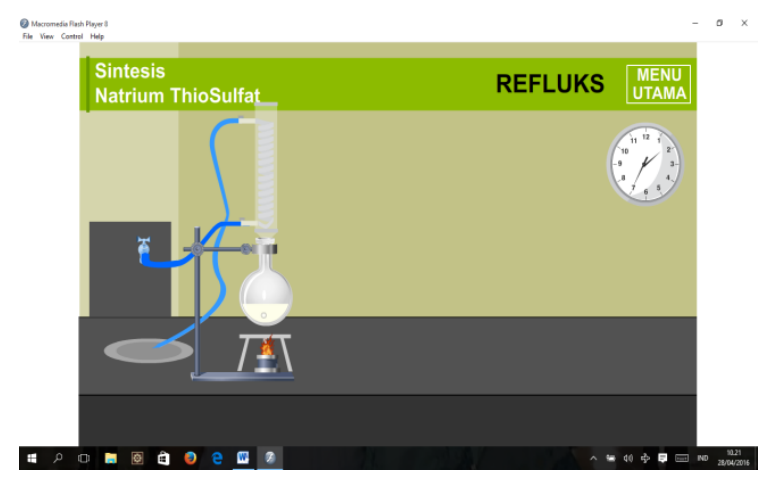

Fig.2. Reflux Experiment in VCL

Virtual experiments that were inputted in the VCL are made so that they resemble the real experiments. But limitations are very likely to be seen because it was not easy to match the conditions of real experiments, in the virtual condition. The VCL was also designed so that the conditions during the experimental process have variations in results if the VCL user does not experiment accurately and carefully. 


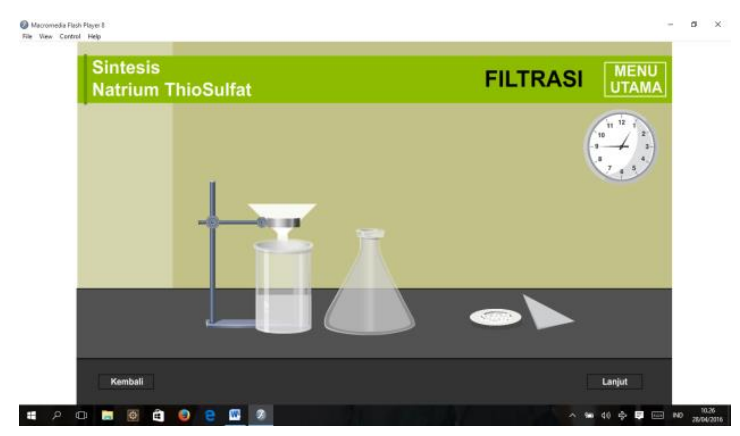

Fig. 3. Filtration Crystal in VCL

Figure 3 showed the process of managing the synthesized compound to obtain the required crystalline chemical compounds. The results of the experiment were made according to circumstances where the synthesis could not be in line with expectations. For example, improper weighing will result in the quantitative identification of synthetically produced compounds of low purity, or improper extraction of substances will cause amorphous crystals of compounds formed. So that, the characterization of compounds was also used as content in VCL to ensure the success of the process to the end.

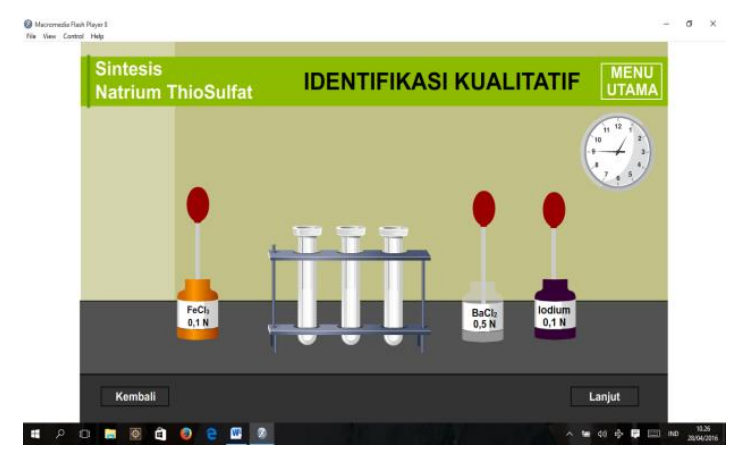

Fig .4. Prediction Skills Supplement in VCL

Figure 4 showed an example of a menu related to the characterization of the synthesized compound, which was related to the identification compounds, qualitatively. This characterization menu at this VCL was provide to supporting or improving student prediction skills.

\subsection{Implementasi VCL}

The VCL implementation in measuring the predictive ability of prospective chemistry teacher candidates in the sample class given a different practicum method is shown in Figure 4. 


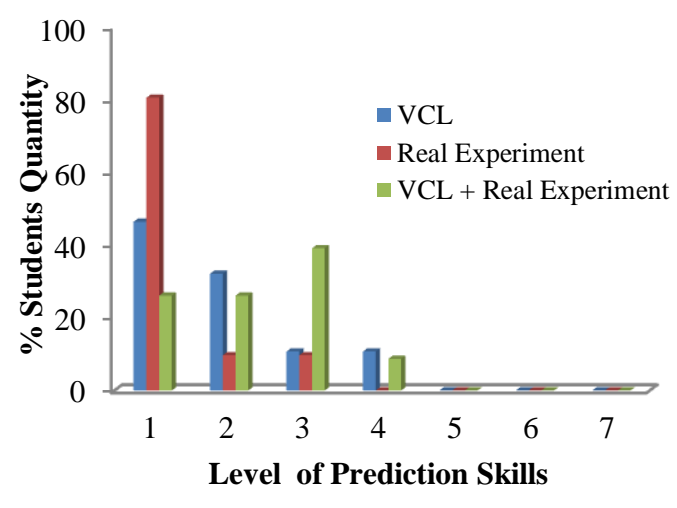

Fig. 5. Prediction Skills of Preservice ChemistryTeacher

The picture above showed that the VCL class gives more stimulants to students' predictive skills, compared to the real experiment class. The majority of students (80.6\%) in class B are on a scale of 1 , or cannot provide predictions at all when the experiment takes place. In the real experimental class, none of the students reached the scale of 4 , only less than $20 \%$ of students were able to predict, even though half of the explanations were very common. The difference seen in the three test classes is the more dominance of the number of students who are on scale 1 in the real experiment class and VCL, despite the significant differences on scale 2 where the VCL class is much higher than the real experiment class. In the VCL + Real Experiment class students' prediction skills were more dominant on a scale of 3 because they provide pre-lab experiences to students. The VCL + Real Experiment class shows the same predictive skills scale on a scale of 1 and 2 , as well as the dominance of students who are at level 3. Compared to the real experimental class, VCL as pre-lab experience has higher scale distributed on almost all scales.

Figure 5 also showed that the role of VCL as predictive stimulants has a synergistic role if it fuctioned as a pre-lab experience by continuing to carry out real experiments, because the fact that students who did real experiment activities are only able to help the majority of students get a scale of 1,2, and a few students at scale 3 and 4 . The implementation of VCL alone without being followed by real experiments was only able to help the majority of students gain skills on a scale of 1 and 2 as well as a few students on a scale of 3 and 4 , although in quantity relatively better than the real experimental class. However, the VCL implementation in reality cannot measure the ability of students in actual experiments, although it can helped them provide more experience that were difficult for them to do that in real experiments due to time constraints and the cost of experiments in the synthesis of certain inorganic compounds.

Figure 5 also showed that none of the students who have predictive skills scales on a scale of 5, 6 and 7, namely the ability scale that shows students can provide precise explanations added to the basic principles of theoretical thinking, focus on context factors with broad considerations. This scale was indeed the highest level in reflective thinking which seems difficult to implement in laboratory activities for 4th semester of preservice chemistry teacher.

Previous research conducted by Seng 2004 also showed a relevant result where the results of measurements of students' reflective ability in practical activities only get the highest score up to a scale of $0.07 \%$, with the condition of the ability to reflect reflective dominantly 
on scales 1, 2 and 3. In conclusion, Seng suggested that research be conducted in the formulation of a strategy and program that could help improve students' reflective thinking skills which could be a link between improving the ability to experiment with reflective thinking.

The VCL development in this study provides answers to this, where students' reflective thinking skills are not dominant at all on a scale of 1 and are more dominant on a scale of 2, 3 and 4, in VCL classes are continued with real experiments where VCL becomes a prediction skills stimulant that can help students predict the results of experimental activities through an analysis of experimental experiences when related to the concept of science.

This study also showed that VCL as pre-lab experiences was able to stimulate students' abilities to the level of quasi reflective as shown in Figure 6.

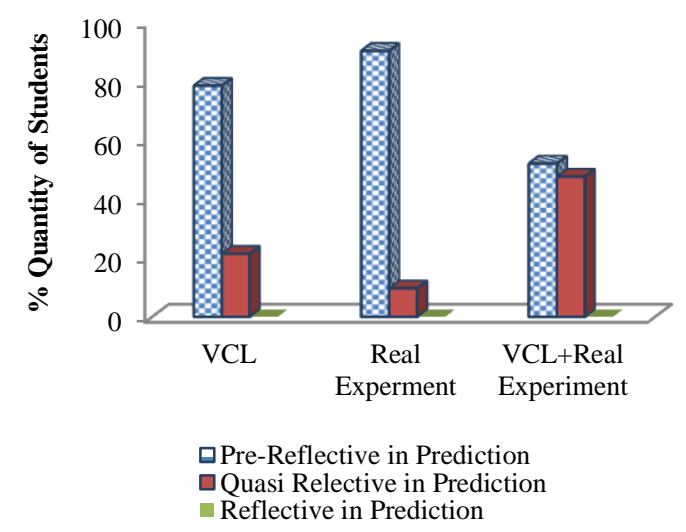

Fig .6. Level of Students Relective Thinking in Prediction

This level of student reflective thinking will generally showed the level of students' reflective thinking skills in each class, after conducting an experimental activity of synthesizing inorganic compounds. Levels 1-3 are categorized as pre-reflective levels, level 45 which are included in the level of quasi reflective level and level 6-7 which are included in the reflective level. The findings of this study indicate that the pre-reflective level of the students was still dominant, if viewed from the indicator of predictive skills, the level of reflective thinking in the class that implements VCL tends to be better followed by real experiments, and the lack of students who have reflective level skills. It means, pre-lab experiences continuously was needed.

In this study, we analysed more deeply about the accuracy and precision of students in making predictions, and how they making decision with bridging concept with experiment, reflectively. The results were obtained in this research as shown in Table 2. 
Table 2.[ Percentage of Students Accuracy and Precision Ability in Prediction

\begin{tabular}{lllllll}
\hline \multirow{2}{*}{$\mathrm{S}$} & \multicolumn{2}{c}{$\mathrm{VCL}$} & \multicolumn{2}{c}{$\mathrm{RE}$} & \multicolumn{2}{c}{ VCL+ RE } \\
\cline { 2 - 7 } $\mathrm{c}$ & Acc & Pres & Acc & Pres & Acc & Pres \\
\hline 1 & 0,0 & 0,0 & 10,8 & 9,7 & 0,0 & 0,0 \\
2 & 52,4 & 67,9 & 63,4 & 61,3 & 36,2 & 43,5 \\
3 & 21,4 & 21,4 & 12,9 & 19,4 & 21,7 & 21,7 \\
4 & 22,6 & 10,7 & 12,9 & 9,7 & 3 & 34,8 \\
5 & 3,6 & 0,0 & 0,0 & 0,0 & 11,6 & 0,0 \\
6 & 0,0 & 0,0 & 0,0 & 0,0 & 0,0 & 0,0 \\
7 & 0,0 & 0,0 & 0,0 & 0,0 & 0,0 & 0,0 \\
\hline
\end{tabular}

The table above shows that the pre-lab experience by VCL provides support to students in terms of accuracy better than precision in predicting. The accuracy of students is better, but they still have difficulties in terms of precision. This research showed that VCL should not be designed only with the intention to replace the role of real experiment, but it was an effort so that students can prepare knowledge, develop skills, alignment and adjustment with real experimental equipment - so they can have great added value as an experiment for experimentation. the real, or when the equipment is rare, dangerous or expensive. VCL also offers simultaneous access to all classes and can be repeated as often as desired without worrying about costs and running out of material(Singh, Sampath, \& Sivaswamy, 2009).

The position of Virtual Chemistry Laboratory is unsubstitutable, in the sense that it does not replace real experiments. It can work as a demonstration and students experiment, or experiment in what works in cyberspace that provides motivation, information about the object under study, information about the truth of the contents of the learning, tasks that contain problems to be solved, so that experimental activities can be improved and they can improve various functions in the cognition process, determining the single phase of observation focused on finding basic features observed by objects or systems, working outside the cognitive process, including experiments in chemistry, which are understood as a form of modeling, analyzing experiments as cognition methods, especially in terms of their functions in the cognition process, and contains practical activities in carrying out experiments on problem solving instruction(Bílek \& Skalická, 2010).

Real experiments should not be for any reason removed from school laboratory practices (Bílek and Skalická 2010) because they shape and improve hands-on skills (measuring by laboratories available instruments, working with laboratory systems, daily use, working with safe and others). A large part of natural science education, can not be replaced completely by practicing through monitors and keyboards. On the other hand, hands-on skills cannot replace direct observation and work with models and instruments.

This VCL of course still needs further development to improve the quality for learning. We have to develop the appearance of concepts that require more micro-scale animation, the addition of simple synthesis experimental content that can train students' broader reflective thinking skills, the addition of student practice questions, and the simulation of the addition of tools and materials that can affect the synthesis results and impact on depth of student mastery of prediction skills. 


\section{Conclusions}

The research conclusions were VCL which are designed with manipulative experiment design in MER way, could help students experience of reflective thinking process to stimulate prediction skills with carefully constructed the content structure in accordance with students' abilities and needs. The implementation of VCL which was continued with real experiment was very helpful to stimulate students' prediction skills. However, this skillscan only increase on a scale of 1 to 2 , with levels that have not reached reflective. Students are also better at accuracy than precision in predicting experimental results

\section{References}

[1]Aksela, M. 2005. Supporting Meaningful Chemistry Learning and Higher-order Thinking through Computer-Assisted Inquiry: A Design Research Approach. Thesis. University of Helsinki, Hesinki.

[2]Ay, Ö. S., \& Yilmaz, S. 2015. Effects of Virtual Experiments Oriented Science Instruction on Students ' Achievement and Attitude,Turkish Online Journal of Educational Technology, 14(2), 609620 .

[3]Babateen, H. M. 2011. The role of Virtual Laboratories in Science Education,International Online Journal of Education Sciences, 12, 100-104.

[4]Bakar, N., Zaman, H. B., Kamalrudin, M., Jusoff, K., Khamis, N., Jaya, H. T. 2013. An Effective Virtual Laboratory Approach for Chemistry,Australian Journal of Basic and Applied Sciences,7(3), 78-84.

[5]Bílek, M., \& Skalická, P. 2010. Combination of real and virtual environment in early chemistry experimental activities, XIV IOSTE, June 13-14.

[6]Dalgarno, B., Bishop, A. G., Adlong, W., \& Bedgood, D. R. 2009. Computers \& Education Effectiveness of a Virtual Laboratory as a preparatory resource for Distance Education chemistry students. Computers \& Education, 53(3), 853-865.

[7]El-sabagh, H. A. E. 2011. The Impact of a Web-Based Virtual Lab on the Development of Students ' Conceptual Understanding and Science Process Skills. Dissertation. Dresden University of Technology, Egypt.

[8]Fariza Khalid. 2015. Reflective Thinking: An Analysis of Students 'Reflections on Their Learning about Computers in Education. Creative Education, 11,,2160-2168.

[9]Herga, N. R., Cagran, B., \& Dinevski, D. 2016. Virtual laboratory in the role of dynamic visualisation for better understanding of chemistry in primary school. Eurasia Journal of Mathematics, Science and Technology Education, 12(3), 593-608.

[10]Hovakimyan, A., Sargsyan, S., Ispiryan, N., Khachoyan, L., \& Darbinyan, K. 2013. An approach to virtual laboratory design and testing, Journal ofSoftware Engineering and Applications. 2(1), 1923.

[11]Keller, H. E., \& Keller, E. E. 2005. Making Real Virtual Labs,The Science Education Review,4(1), 2-11.

[12]King, F., Goodson, L., \& Rohani, F. 2004. Higher Order Thinking Skills • Definition • Teaching Strategies - Assessment. A publication of the Educational Services Program. Retrieved from www.cala.fsu.edu

[13]Kurniawati, Y. 2017. Pengembangan virtual experiment sintesis senyawa anorganik sebagai jembatan interelasi penguasaan konsep, berpikir reflektif, dan bereksperimen pada mahasiswa calon guru kimia.Dissertation, Bandung, Universitas Pendidikan Indonesia.

[14]Kurniawati, Y., Permanasari, A., Muzakir, A., \& Rohman, I. 2015. Potential of Reflective Thinking Skills as a Bridge for Students ' Prior-Knowledge and Chemistry Experiments Skills, IJSR, 4(9), 216-221.

[15]Levy, S. T., \& Wilensky, U. 2009. Students' learning with the connected chemistry (CC1) curriculum: Navigating the complexities of the particulate world. Journal of Science Education and Technology, 18(3), 243-254.

[16]Paul, R., \& Elder, L. 2005. Critical Thinking Competency Standard. Foundation for Critical 
Thinking.

[17]Rodgers, C. 2002. Defining_Reflection: Anoother Look at John Dewey and Reflective Thinking. Teacher College Record, 104(4), 842-866.

[18]Schaeffer, L. R. 2011. Prediction Theory, 07762(732), 84. Retrieved from http://www.aps.uoguelph.ca/ Irs/ABModels/

[19]Schon, D. A. (1983). The reflective practitioner -. In Learing I Teams (pp. 1-8). Retrieved from www.sopper.dk/speciale/

[20]Singh, J., Sampath, H., \& Sivaswamy, J. 2009. An Open Source Virtual Lab for School Physics Education. The National Conference on Open Source Software, (May).

[21]Sirhan, G., Reid, N., Phillips, D., Overton, T. L., Garratt, J., Tomlinson, J., ... Domin, D. S. 2001. University Chemistry Education, 5(2).

[22]Sparks-Langer, G. M., Simmons, J. M., Pasch, M., Colton, A., \& Starko, A. (1990). Reflective Pedagogical Thinking: How Can We Promote It and Measure It? Journal of Teacher Education, 41(5), 23-32.

[23]Strampel, K., \& Oliver, R. 2007. Using technology to foster reflection in higher education. ICT: Providing Choices for Learners and Learning. Proceedings Ascilite Singapore 2007., (1994), 973[24]Tatli, Z., \& Ayas, A. 2013. Effect of a Virtual Chemistry Laboratory on Students' Achievement. Educational Technology \& Society, 16(1), 159-170. Retrieved from http://www.ifets.info/journals/16_1/14.pdf 